\title{
Through the looking glass: the diverse in vivo activities of chemokines
}

\author{
Steven L. Kunkel \\ Department of Pathology, 1301 Catherine Road, University of Michigan Medical School, Ann Arbor, Michigan 48109-0602, USA. \\ Phone: (734) 936-1020; Fax: (734) 764-2397; E-mail: slkunkel@umich.edu.
}

Just over a decade ago, a small group of scientists was struggling to understand the significance of a human monocytederived neutrophil chemotactic factor (MDNCF)/neutrophil-activating factor (NAF), which possessed peptide sequence similarity to other putative host defense cytokines $(1,2)$. The early structural and biological studies of this factor, which was later named interleukin-8, provided the foundation for our current understanding of the chemistry and functions of a large group of signaling factors, the products of the chemokine supergene families (3). These early investigators, perhaps, failed to anticipate the magnitude of the topic they had begun to study: the term "chemokine" is now taken to encompass 4 different structural families, comprising over 50 ligands that interact with at least 17 different receptors (Figure 1). These chemokine families, named according to the structure of a conserved cysteine-containing motif, are defined by the presence of either a $\mathrm{C}, \mathrm{a} C \mathrm{C}, \mathrm{a} \mathrm{CXC}$, or a $C^{\prime} C$ at their amino terminus of the protein. The largest of these families are the CXC group, in which 2 amino terminal cysteines are separated by a nonconserved amino acid, and the CC group, in which 2 amino terminal cysteines are juxtaposed. In their monomeric form, the majority of chemokines have a molecular weight of approximately $10 \mathrm{kDa}$ and bind specifically to heparin.

The desire by academics, as well as biotechnology and pharmaceutical companies, to establish patent rights on the various chemokines and chemokine receptors has provided the major impetus for cloning their genes and identifying the structure of the gene products. However, these efforts have far outpaced our understanding of both general chemokine biology and the role these novel mediators may play in either homeostasis or in the initiation, maintenance, and resolution of disease. While several investigations have demonstrated that certain chemokines elicit subpopulations of leukocytes, other studies have shown that the induction of leukocyte chemotaxis to sites of inflam- mation is by no means the only activity associated with these molecules. Thus, chemokines play diverse roles, providing mechanisms for lymphocyte development (4), driving cytokine networks (5), altering the expression of adhesion molecules (6), increasing cell proliferation (7), regulating angiogenesis (8), promoting viral-target cell interactions (9), participating in different aspects of cancer (10), supporting the reproductive process (11), regulating hematopoiesis (12), and activating the innate immune system (13).

The intriguing data of Mazzucchelli et al. in this issue of the JCI (14) indicate that chemokines can act in normal homeostasis, as well as in the pathogenesis of specific bacterial diseases. This study implicates the recently described B cell-attracting chemokine-1 (BCA-1) both in normal homing of $\mathrm{B}$ cells to lym- phoid tissue and in the initiation of gastric lymphomas of the mucosa-associated lymphoid tissue (MALT) induced by chronic Helicobacter pylori gastritis. In particular, BCA-1 may provide an important key to understanding the different pathologies associated with Helicobacter pylori infection. It is generally accepted that MALT is not normally found in the stomach mucosa and that the development of gastric lymphomas is rare. Nevertheless, both conditions may develop with chronic Helicobacter infection, and, interestingly, both resolve as the infection is abolished. This sequence of events suggests a strong association between Helicobacter infection, increased BCA-1 expression by both B lymphocytes and follicular dendritic cells, and longevity of the bacteria-associated lymphoid aggregates. These investigations suggest that

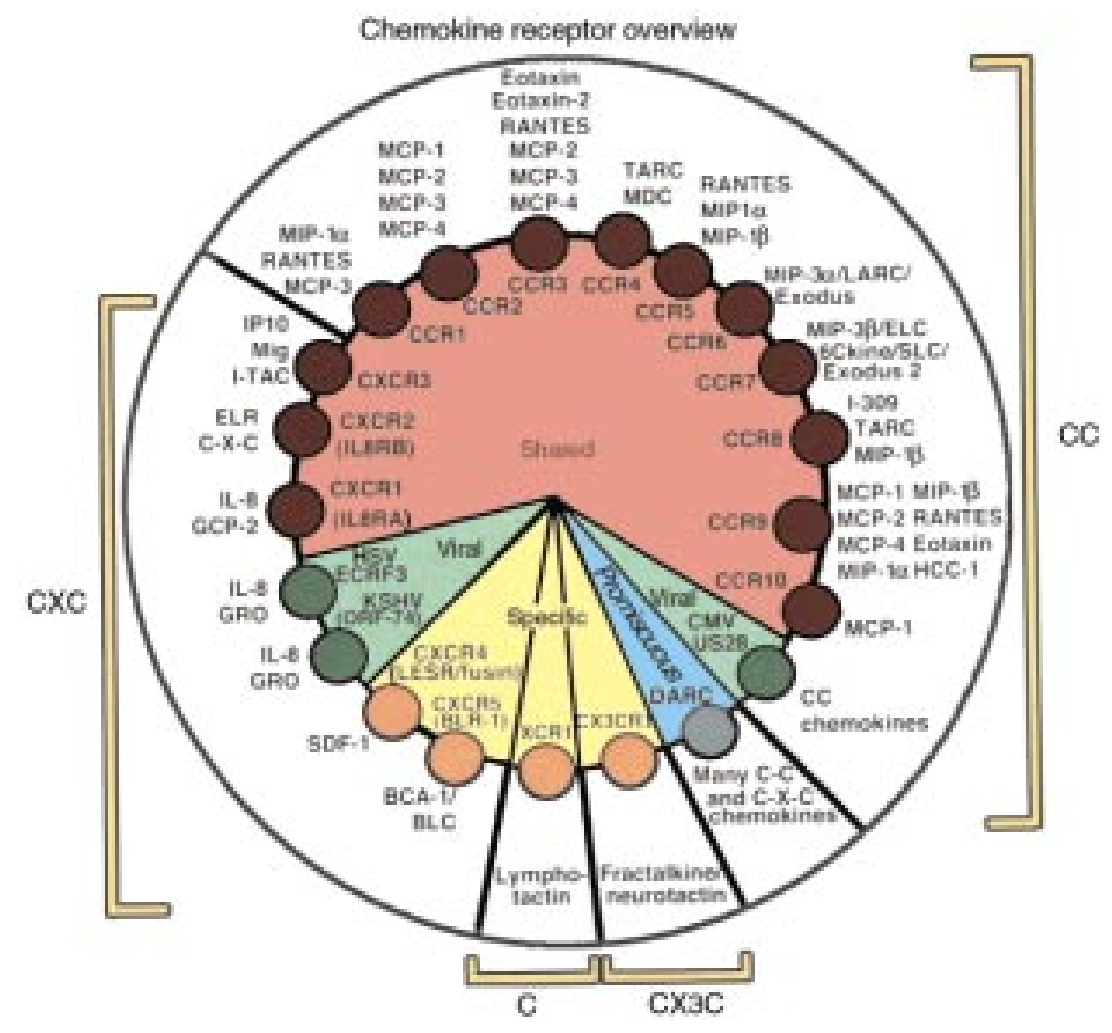

Figure 1

The catalog of known chemokines now includes 4 separate families, with multiple promiscuous ligands binding a variety of structurally related receptors. 
BCA-1 may play a dual role, promoting both B-cell homing during normal conditions and the pathologic accumulation of B cells in Helicobacter-induced disease. The present studies also provide some of the first information correlating bacteria and/or bacterially derived products with the local expression of a specific chemokine and with ensuing B-cell accumulation.

This study is a sequel to early investigations that indicated that the receptor for BCA-1 (CXCR5) is highly expressed on circulating blood B lymphocytes and on Burkitt's lymphoma cells, and that mice deficient in this receptor do not have normal follicle and germinal center formation in the spleen and Peyer's patches (15-17). Thus, the precedent for BCA-1/CXCR5 expression and the elicitation of B cells had been established, but the potential contribution of this ligand/receptor pair in the pathology of specific diseases had not been well explored. It should be underscored that the biology of B-cell homing and chemotaxis is not well understood and that all of the above studies have provided significant insight toward defining this biological phenomenon.

As manuscripts relating to the structure, function, and in vitro cell biology of chemokines fill volumes of scientific journals, investigations like those by Mazzucchelli et al. begin to address the physiological relevance of chemokines. Taking a broad view of the field, chemokine researchers have developed a wealth of recombinant proteins, neutralizing antibodies, and genetically altered mice; with these tools, they have learned something about a few members of the chemokine family, but very little about most of them. As the last decade has provided researchers with a plethora of ligand and receptor targets to study, the next decade will likely provide a more complete understanding of the complex role that chemokines play in vivo in homeostasis and disease.

As Alice said after reading the poem "Jabberwocky" in Through the Looking Glass and What Alice Found There, "It seems very pretty, but it is rather hard to understand!" (You see she didn't like to confess, even to herself, that she couldn't make it out at all.) "Somehow it seems to fill my head with ideas only I don't exactly know what they are!"

1. Yoshimura, T., Matsushima, K., Oppenheim, J.J., and Leonard, E.J. 1987. Neutrophil chemotactic factor produced by lipopolysaccharide (LPS)-stimulated human blood mononuclear leukocytes: partial characterization and separation from interleukin-1 (IL1). J. Immunol. 139:788-793.

2. Walz, A., Peveri, P., Aschauer, H., and Baggiolini, M. 1987. Purification and amino acid sequencing of NAF, a novel neutrophil-activating factor produced by monocytes. Biochem. Biophys. Res. Commun. 149:755-761

3. Lindley, I.J.D., Westwick, J., and Kunkel, S.L. 1993. Nomenclature announcement: the chemokines. Immunol. Today. 14:24.

4. Campbell, J.J., Pan, J., and Butcher, E.C. 1999. Cutting edge: developmental switches in chemokine responses during $\mathrm{T}$ cell maturation. J. Immunol. 163:2353-2357.

5. Sherry, B., Horii, Y., Manogue, K.R., Widmer, U., and Cerami, A. 1992. Macrophage inflammatory proteins 1 and 2: an overview. Cytokines.
4:117-130.

6. Huber, A.R., Kunkel, S.L., Todd, R.F., and Weiss, S.J. 1991. Regulation of transendothelial neutrophil migration by endogenous interleukin-8. Science. 254:99-102.

7. Hogaboam, C.M., et al. 1999. Novel CXCR2dependent liver regenerative qualities of ELRcontaining CXC chemokines. FASEB J. 13:1565-1574.

8. Strieter, R.M., et al. 1995. The functional role of the ELR motif in CXC chemokine-mediated angiogenesis. J. Biol. Chem. 270:27348-27357.

9. Cocchi, F., et al. 1995. Identification of RANTES MIP-1 alpha, and MIP-1 beta as the major HIVsuppressive factors produced by CD $8+\mathrm{T}$ cells. Science. 270:1811-1815.

10. Luca, M., et al. 1997. Expression of interleukin-8 by human melanoma cells up-regulates MMP-2 activity and increases tumor growth and metastasis. Am. J. Pathol. 151:1105-1113.

11. Garcia-Celasco, J.A., and Arici, A. 1998 Chemokines and human reproduction. Fertil. Steril. 71:983-993.

12. Broxmeyer, H.E., and Kim, C.H. 1999. Regulation of hematopoiesis in a sea of chemokine family members with a plethora of redundant activities. Exp. Hematol. 27:1113-1123.

13. Hachicha, M., Rathanaswami, P., Naccache, P.H., and McColl, S.R. 1998. Regulation of chemokine gene expression in human peripheral blood neutrophils phagocytosing microbial pathogens. $J$ Immunol. 160:449-454.

14. Mazzucchelli, L., et al. 1999. BCA-1 is highly expressed in Helicobacter pylori-induced mucosaassociated lymphoid tissue and gastric lymphoma. J. Clin. Invest. 104:R49-R54.

15. Forster, R., Emrich, T., Kremmer, E., and Lipp, M 1994. Expression of the G-protein coupled receptor BLR1 defines mature, recirculating B cells and a subset of T-helper memory cells. Blood. 84:830-840.

16. Forster, R., et al. 1996. A putative chemokine receptor, BLR1, directs $\mathrm{B}$ cell migration to defined lymphoid organs and specific anatomic compartments of the spleen. Cell. 87:1037-1047.

17. Legler, D.F., et al. 1998. B cell-attracting chemokine 1, a human CXC chemokine expressed in lymphoid tissues, selectively attracts B lymphocytes via BLR1/CXCR5. J. Exp. Med. 187:655-660. 